\title{
Editorial
}

\section{¿A quién corresponde?}

\author{
Dr. Mohammad Hasan Abed-Raduan
}

I Especialista en Anestesiología y Recuperación. Subespecialista en Anestesia Pediátrica.
ISSN 0001-6002/2004/46/1/6

Acta Médica Costarricense,(C2004

Colegio de Médicos y Cirujanos
El dolor crónico, especialmente para el paciente en estado terminal, enfrenta retos mayores cada día. El mismo paciente y su entorno sufren modificaciones diarias por este dolor físico-psicosocial. La función de la medicina paliativa es hacer de este periodo tan doloroso, una etapa con el menor sufrimiento posible, preservando la dignidad de las personas y procurando un nivel aceptable de la calidad de vida; sin embargo, esto no es fácil por varias razones.

El entorno familiar debe ser solidario, con altas dosis de amor y tolerancia, lo que exige modificar la educación actual, pues prevalece el concepto de que "los viejitos" y los incapacitados que no producen, son un estorbo; eso se logra predicando con el ejemplo, en el mismo seno de la familia.

Es preciso desarrollar las clínicas del tratamiento del dolor crónico, como un concepto multidisciplinario en la práctica diaria, sin divorciarlo de la teoría.

Se requiere dinamizar el tratamiento del dolor, sin aplicar modelos regidos por la severidad del síndrome doloroso. Aunque hay que seguir directrices, no por eso el paciente y sus familiares deben experimentar grandes sufrimientos para llegar al punto de mitigar la pena.

Es necesario que se de un seguimiento humanizado, haciendo accesibles las citas en cortos periodos, y no en plazos de meses, como sucede en el Seguro Social, donde se conocen casos de pacientes que sufren grandes dolores, por que se les aplicaba rígidamente la famosa y mal entendida escalera del tratamiento del dolor crónico, propuesta por la Organización Mundial de Salud (OMS), de modo que cuando les tocaba el control, ya habían fallecido, sumidos en tremendos dolores, por lo que la aplicación del algoritmo terapéutico es muy importante.

Urge elaborar investigaciones y estadísticas en el ámbito nacional, para retroalimentar y tener una idea de lo que se está haciendo; de lo contrario se trabajará a ciegas, sin saber lo bueno o malo que se hace.

Revisiones como la que se incluye en esta edición sobre el dolor óseo, son fundamentales, pues este tipo de dolor no es poco frecuente, su manejo es difícil y la comprensión de su fisiopatología conlleva a las medidas terapéuticas adecuadas.

Ahora, en relación con la pregunta planteada inicialmente, ¿a quién corresponde atender el tratamiento del dolor crónico?, se debe partir del hecho de que se trata de un sufrimiento físico, psíquico y social, por lo que queda claro que el equipo debe incluir médicos de varias especialidades y profesionales de otras áreas: médicos generales, internistas, alergólogos, neurólogos, neurocirujanos, anestesiólogos, enfermeras, psicólogos, sociólogos y religiosos, en estrecha colaboración con personal de apoyo farmacólogos, fisioterapistas y las demás ramas de las especialidades médicas. Es una labor compleja y costosa, a sabiendas de que los recursos asignados para tal fin son raquíticos, y de que se trabaja muchas veces con base en donaciones. Los insumos para el tratamiento adecuado y la formación de personal para estas clínicas, deben considerarse con seriedad por parte de los jerárcas políticos y administrativos de las entidades de salud del país. 